forwards on to the clivus, while lesions such as the clivus meningioma will displace it away from the skull base.

The cases described in this paper illustrate how complete the remission may be in both gliomas and vascular tumours. The mechanism of the relapses and remissions is uncertain, but presumably is similar to that seen in tumours elsewhere in the nervous system-necrosis and oedema in the tumour itself, haemorrhage into or around it, and necrosis and oedema in the surrounding brain tissue due to the involvement of the small blood-vessels. Such oedema might be influenced by corticotrophin and so give an apparent therapeutic response and reinforce the diagnosis of demyelinative disease. Certainly in Cases 1 and 2 there was involvement of the vertebral artery and Case 3 showed cystic degeneration. Hormonal influences may also play a part. Bickerstaff et al. (1958) showed how clearly the behaviour of some parasellar meningiomas can be related to pregnancy and menstruation, and a similar mechanism may be felt at any site where only a slight enlarge- ment of the tumour is required to produce a dramatic increase in symptoms.

It is the awareness of the possibility that such remissions may occur that is important, and the realization that though, like lightning, multiple sclerosis may strike more than once in exactly the same place such an event should raise great doubts about the diagnosis and stimulate full neuroradiological investigation.

We thank Dr. J. McDonald Holmes for permission to report his case and Miss S. Ray for her help at various stages.

\section{REFERENCES}

Bickerstaff, E. R., Small, J. M., and Guest, I. A. (1958). Fournal of Neurology, Neurosurgery, and Psychiatry, $21,89$.

Ford, F. R. (1966). Diseases of Nervous System in Infancy, Childhood, and Adolescence, 5 th ed. Thomas, Springfield, Illinois.

Sachs, E. (1949). Diagnosis and Treatment of Brain Tumours and Care of the Neurosurgical Patient, 2nd ed. Mosby, St. Louis.

\title{
Role of Candida albicans Infection in Napkin Rashes
}

\author{
P. N. DIXON,* M.B., D.P.H. ; R. P. WARIN, $\dagger$ M.D., F.R.C.P.; MARY P. ENGLISH, $\ddagger$ M.SC. \\ With the Technical Assistance of LiNDA GRENFEll
}

British Medical fournal, 1969, 2, 23-27

\begin{abstract}
Summary : Skin scrapings, mouth swabs, and faecal $S$ specimens from children with eruptions in the napkin area and from a series of normal infants were examined for the presence of Candida albicans.

This was found in $41 \%$ of all napkin eruptions but in only one of the 68 normal infants. While C. albicans is a common secondary invader of all types of napkin eruption, primary candida infection of the skin in the napkin area is probably uncommon.

No evidence was found that generalized psoriasiform or eczematous eruptions occurring in association with napkin rashes are due $t$ an allergic response to the fungus. C. albicans is more likely to be present in a napkin rash if the organism has been found in the alimentary tract.
\end{abstract}

\section{Introduction}

Four main types of napkin eruption are usually described, and include the common napkin rash due mainly to irritation by ammonia, seborrhoeic (intertriginous) eczema, a psoriasislike eruption (napkin psoriasis), and an eruption reported as a primary Candida albicans infection. C. albicans is well recognized as an opportunist organism growing where general and local conditions are favourable, and among these conditions moisture and a pre-existing skin disorder are important. C. albicans has been recovered from the alimentary tract of up to $31 \%$ of infants under the age of 9 months (Beare, Cheeseman, and Mackenzie, 1968), and it is therefore not surprising that the organism has been isolated from napkin rashes of all types. When so discovered $C$. albicans may well be accepted as having a primary role in the napkin eruption, and psoriasiform or

* Assistant Medical Officer, City and County of Bristol.

† Dermatologist, United Bristol Hospitals.

‡ Mycologist, United Bristol Hospitals. eczematous lesions which may develop in other sites of the body have often been considered to be either a spread of the infection or an allergic response to the fungus.

In the present investigation we compare the prevalence of $C$. albicans infection of the skin and alimentary tract in children with different patterns of napkin eruption and in a series of normal controls. Our purpose was to determine, firstly, whether infections of the skin in the napkin area by C. albicans were more likely to be primary or secondary in origin, and, secondly, whether there is any evidence for a causal relationship between $C$. albicans infection and generalized psoriasiform or eczematous eruptions.

\section{Material}

The cases included in the investigation were either referred by their doctors to the dermatological outpatient department of one of the Bristol hospitals or were attending certain of the local authority's child welfare clinics. Very little further selection was made. All children with a napkin eruption who attended the dermatological clinic at the Royal Hospital for Sick Children during the period of the investigation were included. Occasionally in child welfare clinics time did not permit the inclusion of some children with a napkin rash, but this happened only rarely.

Group I. Napkin Psoriasis.-Of the 27 cases in this group 24 were referred to the Royal Hospital for Sick Children between April 1967 and June 1968 and three were seen at other hospitals. The eruption usually starts in the napkin area, often mainly on the napkin contact sites, and consists of patches of brown-red skin with some scale and well-marginated figurate edges often enclosing areas of normal skin. Lesions of up to $10 \mathrm{~cm}$. in diameter or larger, all with well-defined edges, then develop on the trunk and limbs and usually the scalp, 
where the scale becomes heaped up. In addition, in some cases patches of redness and scaling may appear in the retroauricular, neck, and axillary creases. The cases accepted in this group all had the psoriasis-like eruption in the napkin area and sites elsewhere.

Group II. Seborrhoeic Eczema.-Of the 22 cases in this group 14 were referrals to the Royal Hospital for Sick Children and eight were encountered in child welfare clinics. In the napkin area redness and scaling merging with surrounding skin was maximal in the groin and buttock creases rather than on the napkin contact sites, and elsewhere occurred in the retroauricular, neck, axillary, or limb creases, over the scalp, or round the umbilicus, involving all or at least one of these sites. All the cases in this group had eczematous eruptions in the napkin area and sites elsewhere.

It was difficult to decide in which group to place a few cases. In some cases of napkin psoriasis and seborrhoeic eczema each type of eruption was present in different areas or at different times, but each case was allocated to the appropriate group according to the predominant type of eruption.

Group III. Napkin Rash.-The third group of 68 cases had napkin rashes alone. Four were seen at the Royal Hospital for Sick Children and 64 in child welfare clinics. In the majority the cruption was present on the main napkin contact sites round the waist, on the inner surface of the thighs where the edge of the napkin presses, and on the buttocks. In some the groin and buttock creases were also involved, but in 30 the eruption was confined to the napkin contact sites, and this subgroup is considered later. It was difficult to differentiate some cases of ammoniacal napkin rash from seborrhoeic eczema, but unless lesions were present in other sites the cases were included in the napkin rash group.

A further difficulty in the investigation has been to separate out a napkin eruption which clinically was primarily a C. albicans infection. In any of the different patterns of napkin rash clinical candida infection was suspected in some cases, but at the same time there was a typical eczematous or psoriasiform eruption or an eruption on the main napkin contact sites characteristic of the common ammonia dermatitis. We have therefore not found it possible to separate out from the napkin rash group any which might possibly have been described by other workers as primary $C$. albicans infection. This point is mentioned in the discussion.

Group IV. Normal.-In addition to those in the three case groups a series of 68 normal children was drawn entirely from child welfare clinics. So far as possible selection was randomized by including as a control the next infant in napkins to follow a child who had been included in one of the case groups. This was not always possible, and the last 30 infants in the normal series were selected on an age quota designed to give a similar age distribution to that of the napkin rash group.

\section{Method}

Records were made of the past, present, and family history, details of previous local or systemic treatment, the site and severity of the eruptions, and whether there was clinical evidence of $C$. albicans infection of the eruption or in the mouth.

Skin scrapings were taken with a sterile tenotomy knife from all affected sites, from normal skin over the sternum, and in the control group from normal skin in the napkin area. Usually the scrapings were taken directly on to the surface of plates of glucose-peptone agar. Where only very little material could be obtained, and for all scrapings from normal skin, the blade was cut into the culture medium. It was also planned to take scrapings from lesions directly on to slides for microscopy, but suitable material could not always be obtained, sometimes because of the mildness of the eruption but more often because of the presence of ointment which defied attempts at removal.
A mouth swab was taken and a specimen of faeces obtained from all children.

\section{Laboratory Methods}

Skin scrapings were squashed in $20 \% \mathrm{KOH}$, and Gramstained smears were made from faeces. Both were examined microscopically for the blastospores and mycelium or pseudomycelium of yeasts.

All cultures were made on glucose-peptone agar or broth containing $0.05 \mathrm{mg}$. of chloramphenicol per ml. to reduce bacterial contamination. Incubation was at $37^{\circ} \mathrm{C}$. All yeasts isolated were submitted to the serum germ-tube test (Taschdjian, Burchall, and Kozinn, 1960), and if germ tubes were produced the organism was considered to be $C$. albicans. On the rare occasions when the test proved negative, standard procedures for the precise identification of the fungus were carried out.

Skin scrapings and faeces were cultured only on the agar medium. Mouth swabs, on which only very small numbers of yeast cells might be present, were first smeared on agar and then, in case this failed to dislodge the organism, incubated whole in broth; this would allow even a single yeast cell to multiply to detectable numbers. The quantity of yeast isolated on an agar plate was arbitrarily reported as small, moderate, or large. If a positive broth culture was obtained from a mouth swab from which no yeast had been isolated on agar, the quantity was recorded as small.

\section{Results}

The age distribution of the subjects of the investigation is shown in Table I. The sex distribution did not differ significantly from that of the normal population, and there were no statistically significant differences between the mean family sizes of the four groups, nor between the proportions with family histories of eczema or psoriasis (Table II). A smell of ammonia from the used napkins was noticed by the mother in $61 \%$ of cases, but the incidence of this observation was about the same in all three case groups. An ammonia smell was reported in $30(44 \%)$ of the children in the control group.

TABLE I.-Age Distribution of the Subjects

\begin{tabular}{|c|c|c|c|c|c|}
\hline & & $\begin{array}{c}\text { Napkin } \\
\text { Psoriasis }\end{array}$ & $\begin{array}{c}\text { Seborrhoeic } \\
\text { Eczema }\end{array}$ & $\begin{array}{c}\text { Napkin } \\
\text { Rash }\end{array}$ & Normal \\
\hline Age in months & $\left\{\begin{array}{l}\text { Range } \\
\text { Median } \\
\text { Mean }\end{array}\right.$ & $\begin{array}{c}1 \cdot 2-14 \cdot 9 \\
3.63 \\
4.35\end{array}$ & $\begin{array}{c}1 \cdot 2-25 \cdot 1 \\
4 \cdot 70 \\
7.55\end{array}$ & $\begin{array}{c}0 \cdot 5-28 \cdot 4 \\
4 \cdot 37 \\
5 \cdot 37\end{array}$ & $\begin{array}{c}0 \cdot 6-23 \cdot 4 \\
4 \cdot 22 \\
5 \cdot 31\end{array}$ \\
\hline Total in group & & 27 & 22 & 68 & 68 \\
\hline
\end{tabular}

\begin{tabular}{|c|c|c|c|c|}
\hline & $\begin{array}{l}\text { Napkin } \\
\text { Psoriasis }\end{array}$ & $\begin{array}{c}\text { Seborrhoeic } \\
\text { Eczema }\end{array}$ & $\begin{array}{c}\text { Napkin } \\
\text { Rash }\end{array}$ & Norma! \\
\hline $\begin{array}{l}\text { History of eczema } \\
\text { History of psoriasis }\end{array}$ & $\begin{array}{l}5 \\
1\end{array}$ & $\begin{array}{l}7 \\
1\end{array}$ & $\begin{array}{r}11 \\
4\end{array}$ & $\begin{array}{r}17 \\
2\end{array}$ \\
\hline Total in group & 27 & 22 & 68 & 68 \\
\hline
\end{tabular}

Fungi other than $C$. albicans were found in various sites in three children. One child with seborrhoeic eczema had $C$. krusei in the mouth and in scrapings from the napkin eruption and from an eczematous lesion of the neck; and the same organism was isolated from the napkin eruption and the faeces of a child in the napkin rash group. These findings do not affect the overall results of the investigation and have not been included in the results. Trichosporon cutaneum, which can be disregarded, was isolated from the faeces of a third child. 


\section{Clinical Appraisal}

From the clinical appearance it was thought that $C$. albicans infection was present in 43 patients distributed fairly evenly between the three groups (Table III). Such a clinical appraisal was supported in many cases but not all by the laboratory results, $C$. albicans being isolated in various quantities from $27(63 \%)$ of these cases. The organism was not isolated from $42(75 \%)$ of the 56 who clinically were thought not to have a C. albicans infection.

TABLE III.-Likelihood of the Presence of C. albicans in Napkin Eruptions, fudged on Clinical Appearance

\begin{tabular}{|c|c|c|c|c|c|}
\hline \multicolumn{2}{|c|}{ Clinical Appearance } & $\begin{array}{l}\text { Napkin } \\
\text { Psoriasis }\end{array}$ & $\begin{array}{c}\text { Seborrhoeic } \\
\text { Eczema }\end{array}$ & $\underset{\text { Rash }}{\text { Napkin }}$ & Total \\
\hline $\begin{array}{l}\text { Candida likely. } \\
\text { Candida possible } \\
\text { Candida unlikely }\end{array}$ & $\begin{array}{l}. \\
\therefore\end{array}$ & $\begin{array}{rr}13 & (6) \\
4 & (2) \\
10 & (5)\end{array}$ & $\begin{array}{rr}6 & (4) \\
2 & (1) \\
14 & (1)\end{array}$ & $\begin{array}{l}24(17) \\
12(4) \\
32(8)\end{array}$ & $\begin{array}{l}43(27) \\
18(7) \\
56(14)\end{array}$ \\
\hline Total & $\ldots$ & $27(13)$ & $22(6)$ & $68(29)$ & $117(48)$ \\
\hline
\end{tabular}

Figures in parentheses are the numbers from whom C. albicans was cultured from the napkin area.

Clinical diagnoses were less frequently confirmed in the napkin psoriasis group. If we ignore those cases where C. albicans infection was thought to be possible and consider only those where it was thought to be likely or unlikely, clinical appraisal was confirmed by the results of culture in 11 out of $23(48 \%)$ in the napkin psoriasis group and in 58 out of 76 $(76 \%)$ of those in the other two case groups combined. This difference almost certainly arises because the diagnosis of C. albicans infection in the napkin psoriasis group presented special difficulties. In many cases the napkin eruption was so severe and widespread that all detail was obscured. In others the sharply defined edges and small satellite psoriasiform lesions may well have been thought erroneously to have been typical of C. albicans infection. No special conclusions can therefore be drawn from the relative inaccuracy of clinical diagnoses in this group.

\section{Morphology and Quantity of C. albicans}

The frequency with which different quantities of $C$. albicans were found in various sites is shown in Table IV. As discussed below, in interpreting mycological findings it is important to take into consideration the morphology and quantity of C. albicans present at each site.

TABLE IV.-Number of Children in the Four Groups from Whom C. albicans was Cultured in Various Quantities from Different Sites

\begin{tabular}{|c|c|c|c|c|c|c|}
\hline & & \multicolumn{4}{|c|}{ Case Groups } & \multirow[b]{2}{*}{ Normal } \\
\hline & & $\begin{array}{c}\text { Napkin } \\
\text { Psoriasis }\end{array}$ & $\left|\begin{array}{c}\text { Seborrhoeic } \\
\text { Eczema }\end{array}\right|$ & $\underset{\text { Rash }}{\text { Napkin }}$ & $\begin{array}{l}\text { Total } \\
\text { Cases }\end{array}$ & \\
\hline \multirow[t]{2}{*}{ Mouth } & $\left\{\begin{array}{l}+ \\
++ \\
+++\end{array}\right.$ & $\begin{array}{l}9 \\
2 \\
0\end{array}$ & $\begin{array}{l}3 \\
3 \\
2 \\
\end{array}$ & $\begin{array}{l}77 \\
8 \\
4\end{array}$ & $\begin{array}{r}19 \\
13 \\
6 \\
\end{array}$ & $\begin{array}{l}6 \\
4 \\
2 \\
\end{array}$ \\
\hline & Total .. & $11(41)$ & $8(36)$ & $19(28)$ & $38(32)$ & $12(18)$ \\
\hline \multirow[t]{2}{*}{ Faeces } & $\left\{\begin{array}{c}+ \\
+++\cdots \\
+++\end{array}\right.$ & $\begin{array}{l}4 \\
6 \\
1 \\
\end{array}$ & $\begin{array}{l}2 \\
6 \\
0 \\
0\end{array}$ & $\begin{array}{r}99 \\
14 \\
7\end{array}$ & $\begin{array}{r}15 \\
26 \\
8\end{array}$ & $\begin{array}{l}3 \\
7 \\
1\end{array}$ \\
\hline & Total ... & $11(41)$ & $8(36)$ & $30(44)$ & $49(42)$ & $11(16)$ \\
\hline \multirow[t]{2}{*}{$\begin{array}{l}\text { Napkin } \\
\text { area }\end{array}$} & $\left\{\begin{array}{l}++\cdots \\
+++\cdots \\
++\end{array}\right.$ & $\begin{array}{l}2 \\
2 \\
9 \\
\end{array}$ & $\begin{array}{l}0 \\
2 \\
4 \\
\end{array}$ & $\begin{array}{r}7 \\
8 \\
14 \\
\end{array}$ & $\begin{array}{r}99 \\
12 \\
27 \\
\end{array}$ & $\begin{array}{l}0 \\
1 \\
0 \\
0\end{array}$ \\
\hline & Total .. & $13(48)$ & $6(27)$ & $29(43)$ & $48(41)$ & 1 \\
\hline \multirow{2}{*}{$\begin{array}{l}\text { Other } \\
\text { affected } \\
\text { sites }\end{array}$} & $\left\{\begin{array}{l}+ \\
++ \\
+++\cdots\end{array}\right.$ & $\begin{array}{l}6 \\
2 \\
2 \\
\end{array}$ & $\begin{array}{l}2 \\
1 \\
1 \\
\end{array}$ & 三 & $\begin{array}{l}8 \\
3 \\
3\end{array}$ & $\bar{z}$ \\
\hline & Total ... & $10(37)$ & $4(18)$ & - & 14 & - \\
\hline \multirow{2}{*}{\multicolumn{2}{|c|}{ Normal skin $+\ldots$}} & 1 & 1 & 2 & 4 & 0 \\
\hline & Total in group $\quad$.. & 27 & 22 & 68 & 117 & 68 \\
\hline
\end{tabular}

Figures in parentheses are the number of children from whom the organism was i solated expressed as a percentage of the total in the group.

$+=$ Small quantity. $++=$ Moderate quantity. $+++=$ Large quantity.
The relative frequency with which different quantities of the organism were isolated was not the same for all sites. For instance, when present in the napkin area it was most of ten cultured in large quantities, but commonly only small quantities were found in the mouth. As the numbers in some of the subgroups were very small we have in the other tables and in the discussion ignored the reported quantity and considered only the presence or absence of the yeast on culture. It must, however, be mentioned that if analysis is confined to the cases where large quantities of $C$. albicans were isolated the proportions in the three groups are about the same.

Microscopical examination of scrapings from the napkin eruption was possible in only $42(36 \%)$ of those in the three case groups. No yeast was seen in 17 of these, though in two very small quantities of $C$. albicans were subsequently cultured. In the other 25 yeast was present in the mycelial state, and in 24 of these subsequent culture confirmed that the yeast was C. albicans, usually in large quantities. In the twenty-fifth case the culture medium was overgrown by bacteria. The results of microscopy were similar in all three groups: mycelia were seen in napkin rash scrapings in $7(26 \%)$ of those in the napkin psoriasis group, in $4(18 \%)$ of those in the seborrhoeic eczema group, and in $14(21 \%)$ of those in the napkin rash group.

\section{Comparison of Groups}

In the group of normal babies, C. albicans was isolated from the napkin area scrapings in only one of the 68 children. In the three case groups the yeast was isolated from napkin area scrapings in $13(48 \%)$ of those with napkin psoriasis, in $6(27 \%)$ of those with seborrhoeic eczema, and in $29(43 \%)$ of those in the napkin rash group. There are no statistically significant differences between these figures. C. albicans was more often present in severe than in mild napkin rashes, and this may account for the higher frequency of isolations from children with napkin psoriasis, as the eruptions in this group were in general severe and widespread.

\section{Other Sites}

Of the 13 patients with napkin psoriasis who had C. albicans present in the napkin area, $10(77 \%)$ also had the yeast isolated from one or more skin lesions elsewhere, as did four (67\%) of the six children in the seborrhoeic eczema group who had $C$. albicans present in the napkin area. The difference is not significant. In the cases in these two groups in which the organism was not isolated from the napkin eruption, no C. albicans was found in any of the skin lesions elsewhere.

The yeast was isolated from clinically normal skin in only $4(3 \%)$ of the children in the three case groups.

\section{Eruptions in Main Napkin Contact Sites}

Table $\mathrm{V}$ shows the frequency of isolations of $C$. albicans according to the sites within the napkin area involved in the eruption. Of the 33 cases who had the eruption only on the napkin contact sites 11 (33\%) yielded C. albicans compared

TABLE V.-Isolations of C. albicans from Napkin Eruptions Affecting TABLE V.-Isolations of C. albicans from Napkin Eruptions Affecting
Different Sites

\begin{tabular}{|c|c|c|c|c|c|c|c|c|}
\hline \multirow{2}{*}{ Site(s) Affected } & \multicolumn{2}{|c|}{$\begin{array}{l}\text { Napkin } \\
\text { Psoriasis }\end{array}$} & \multicolumn{2}{|c|}{$\begin{array}{c}\text { Seborrhoeic } \\
\text { Eczema }\end{array}$} & \multicolumn{2}{|c|}{$\begin{array}{c}\text { Napkin } \\
\text { Rash }\end{array}$} & \multicolumn{2}{|c|}{ Total } \\
\hline & No. & $\begin{array}{l}\text { Can- } \\
\text { dida }\end{array}$ & No. & $\begin{array}{l}\text { Can- } \\
\text { dida }\end{array}$ & No. & $\begin{array}{l}\text { Can- } \\
\text { dida }\end{array}$ & No. & $\begin{array}{l}\text { Can- } \\
\text { dida }\end{array}$ \\
\hline $\begin{array}{l}\text { Contact areas only } \ldots \\
\text { Creases only } . \\
\text { Creases and contact }\end{array}$ & $\begin{array}{l}0 \\
2\end{array}$ & $\overline{2}$ & $\begin{array}{l}3 \\
4\end{array}$ & $\begin{array}{l}0 \\
1\end{array}$ & $\begin{array}{l}30 \\
15\end{array}$ & $\begin{array}{r}11 \\
6\end{array}$ & $\begin{array}{l}33 \\
21\end{array}$ & $\begin{array}{r}11 \\
9\end{array}$ \\
\hline $\begin{array}{ccc}\text { areas } & \cdots & \ldots \\
\end{array}$ & 25 & 11 & 15 & 5 & 23 & 12 & 63 & 28 \\
\hline Total & 27 & 13 & 22 & 6 & 68 & 29 & 117 & 48 \\
\hline
\end{tabular}


with $9(43 \%)$ of the 21 with lesions confined to the groin and buttock creases. This difference is not significant $(P>0.3)$. If only the napkin rash group is considered, the proportions yielding $C$. albicans from the different sites are almost identical (37\% and $40 \%$ respectively).

\section{C. albicans in Alimentary Tract}

In Table VI the presence of $C$. abbicans in the alimentary tract is compared with its occurrence in the napkin area. In the three case groups $C$. albicans was isolated from the napkin eruption in $71 \%$ of those who had the yeast isolated from the alimentary tract, but it was not found in the alimentary tract of $23 \%$ of those from whom it was isolated from the napkin eruption. There were no marked differences between the three groups.

TABLE VI.- Relationship Between Isolations of C. albicans from the
Alimentary Tract and from the Napkin Area

The overall prevalence of $C$. albicans in the alimentary tract of children in the three case groups was $44 \%$. Fourteen $(21 \%)$ of the 68 normal children had the yeast in the alimentary tract.

\section{Steroids and Antibiotics}

Contrary to expectation, the frequency with which $C$. albicans was isolated from the napkin area did not appear to be increased when there was a history of previous or current treatment with local steroids or local or oral antibiotics. The organism was found in $20 \%$ of those in the three case groups who had had antibiotics, and in $45 \%$ of those who had not. The corresponding figures for steroids were $46 \%$ and $39 \%$.

\section{Age and Sex}

In the napkin rash group $C$. albicans was more likely to be isolated from the napkin eruption of younger rather than older infants. Of those under 4 months of age $59 \%$ yielded the organism, compared with only $28 \%$ of those aged 4 months or more $(P<0.01)$. There was no significant difference between the frequencies with which the yeast was isolated from the two sexes.

\section{Discussion}

\section{Primary Candida Infection}

We have in this investigation failed to show any significant differences between the frequencies with which $C$. albicans was found in the skin or alimentary tract in our three groups of children with napkin eruptions, and this finding allows at least two possible interpretations. Firstly, it is possible that primary C. albicans infection of the skin in the napkin area occurs, and that the resulting eruption can remain confined to the napkin contact sites or it can assume appearances typical of either psoriasis or eczema, perhaps with associated skin lesions elsewhere. Secondly, it could be that $C$. albicans is often present as a secondary invader in napkin rashes of all types.

It has been found impossible to produce experimental infecition of normal adult skin without complete occlusion of the site (Maibach and Kligman, 1962), but it may be that in infants the skin in the napkin area can under normal circumstances become sufficiently macerated to allow $C$. albicans to become established. However, in view of the known predilection of C. albicans for intertriginous areas, we might have expected to find a significantly higher prevalence of the organism in eruptions involving the skin creases than in eruptions which remained confined to the napkin contact sites, but we failed to do so. Furthermore, in those cases where direct microscopy was possible mycelia (the presence of which suggests invasion) were seen in about the same proportion of rashes of all three types. Whether we consider total isolations or only those where there was evidence suggesting invasion, the lack of any significant difference between the frequencies with which $C$. albicans was found in napkin rashes of different clinical types, and involving different sites, suggests that primary candida infection is less common than secondary invasion by the organism of a breach in the epithelium provided by a non-infective napkin eruption. In fact, in those cases where only very small quantities of the yeast were isolated from the napkin area the organism was unlikely to be an invader, whether primary or secondary, but merely a temporary inhabitant of the breached skin which had not been rendered non-viable as a result of desiccation (Marples, 1966).

\section{Napkin Psoriasis}

A further point on which we were anxious to shed light was whether or not $C$. albicans infection had a primary role in the cause of the condition referred to as napkin psoriasis. It has been suggested that the generalized eruption is an "ide" secondary to $C$. albicans infection in the napkin area or alimentary tract (Fergusson, Fraser, and Grant, 1966), but our failure to show any significant differences between the prevalence of $C$. albicans in the three case groups would be against this view. Furthermore, we failed to isolate C. albicans from any site in $10(37 \%)$ of our patients with napkin psoriasis, and it would certainly not be possible to consider an "ide" eruption in those cases.

\section{Sampling Methods}

The significance of isolations of $C$. albicans from the skin or mucous membranes is often debated. Kozinn and Taschdjian (1966) considered that isolations from the skin always indicate the pathogenic role of $C$. albicans. However, some workers have recovered the organism from the skin of a significant proportion of normal infants (Vignec, 1958 ; Beare et al., 1968). This contradiction may be explained by the fact that in these two surveys swabs were taken from the perianal region, where there is a high chance that the fungus was merely a contaminant from the faeces. This seems particularly so, as scrapings from normal skin in the napkin area away from the anus in 30 infants failed to yield the organism (Warin and Faulkner, 1961). If material for microscopy can be obtained the picture may be clearer, as it is generally agreed that the presence of $C$. albicans in the mycelial state in lesions of skin or mucous membrane is a sign of invasion and pathogenesis, while if it is present purely as blastospores it is likely to be a saprophyte. There is, however, no sharp dividing line, and a large quantity of blastospores with no mycelium in a surface lesion could indicate actual or incipient invasion, or the yeast cells may in dying release toxins which can cause eruptions typical of cutaneous candidiasis (Maibach and Kligman, 1962).

In order to make an accurate assessment of the role played by $C$. albicans in any given lesion, its quantity and morphological state should be taken into account. The quantity of yeast isolated on culture can be assessed, but recognition of morphology requires microscopical examination of a suitable specimen, which is often impossible to obtain. It is for this 
reason that we were obliged to base our figures on cultural isolations of $C$. albicans. It is, however, pointed out that where microscopy was possible the results were in keeping with the findings on culture.

\section{C. albicans in the Alimentary Tract}

The significance of isolations of $C$. albicans from the skin or of the sampling techniques used are both relevant to the relationship between the presence of $C$. albicans in the alimentary tract and its isolation from napkin eruptions. It is difficult from our results to define the relationship further than that the presence of the organism in one site, alimentary tract or napkin rash, is likely to be associated with its presence in the other. The association may be more common than our findings suggest if some cultures were regative because the wrong part of the napkin rash was scraped or the wrong portion of faeces was selected.

Our finding that the prevalence of $C$. albicans in the alimentary tract was twice as great in the children in the three case groups $(44 \%)$ as in the normal children (21\%) is not unexpected. Whether $C$. albicans infection of the skin is primary or secondary, it is clearly more likely to occur if the organism is frequently brought into contact with the skin in the napkin area through its presence in the faeces.

\section{Prevalence of C. albicans}

This investigation has shown the presence of $C$. albicans in $41 \%$ of a representative selection of eruptions in the napkin area. Our evidence suggests that the fungus is in most cases present as a secondary invader, though we cannot exclude the possibility that primary candida infection sometimes occurs. In any event its presence is likely to increase the eruption, and its treatment will help a great deal in the management of such napkin rashes.

We are grateful to Professor M. Marples, Dr. C. D. Evans, Dr. R. R. M. Harman, and Dr. A. J. E. Barlow for their advice during the preparation of this report.

Reprints may be obtained from P. N. Dixon, Department of Public Health, University of Bristol, Canynge Hall, Whatley Road, Bristol 8.

REFERENCES

Beare, J. M., Cheeseman, E. A., and Mackenzie, D. W. R. (1968). British fournal of Dermatology, 80, 675.

Fergusson, A. G., Fraser, N. G., and Grant, P. W. (1966). British fournal of Dermatology, 78, 289.

Kozinn, P. J., and Taschdjian, C. L. (1966). Fournal of the American Mach, H. I, and Kligman, A. M. (1962). Archives of Dermatology, $85,233$.

Marples, M. J. (1966). Proceedings of the New Zealand Ecological Society, 13, 29.

Taschdjian, C. L., Burchall, J. J., and Kozinn, P. J. (1960). American fournal of Diseases of Children, 99, 212.

Vignec, A. J. (1958). fournal of Pediatrics, 53, 692.

Warin, R. P., and Faulkner, K. E. (1961). British fournal of Dermato$\log y, 73,445$.

\title{
Juvenile Pernicious Anaemia and Hypothyroidism. A Family Study
}

\author{
R. A. M. OLIVER,* D.M., M.C.PATH. ; G. P. BAKER, $\dagger$ M.D., M.SC., F.R.C.P.
}

Cummary : A man presented with the sudden onset of pernicious anaemia at the age of 21 . He had been treated for hypothyroidism since the age of 6 . His father and only paternal aunt were also found to have pernicious anaemia. Gastric and thyroid antibody studies showed one or more antibodies to be present in all three subjects, as well as in the patient's mother.

\section{Introduction}

The rarity of classical pernicious anaemia and its late age of onset make the study of its possible inheritance difficult. It is still debatable whether this is determined by a dominant or a recessive gene or genes, uncertainty exists regarding the importance of exogenous factors, and there is doubt about the importance in aetiology of antibodies acting on the stomach and other organs. In the largest family study of pernicious anaemia yet published, Callender and Denborough (1957) were able to study both parents in only two instances from 142 families owing to the late age of onset. Although in 19 of their families two proved cases of pernicious anaemia occurred, in only three families were three or more cases found and their family trees illustrated. The occurrence of pernicious anaemia in a man of 21 , who was also suffering from hypothyroidism,

* Consultant Haematologist, Mayday Hospital, Croydon, Surrey. + Consultant Physician, Mayday Hospital, Croydon, Surrey. gave us the opportunity to study the family in some detail, both as regards vitamin $B_{12}$ absorption and serum antibody studies, with results which we feel worthy of record.

\section{Case Report}

A man aged 21 was admitted to hospital in March 1966 for investigation of anaemia. When aged 6 he was diagnosed at Guy's Hospital as suffering from juvenile myxoedema, which was well controlled with thyroid extract. When aged 8 he developed eczema and bronchospasm and was regarded as a case of Besnier's prurigo. In 1965 he had pneumonia and dry pleurisy, and then he developed unticaria, which lasted for several months. He remained well until three weeks before his present admission, when he began to complain of excessive lassitude and some dyspnoea on excretion.

On admission he was pale, but otherwise looked healthy. He was euthyroid and mentally quite normal. He was then taking $0.3 \mathrm{mg}$. of thyroxine daily. Apart from anaemia physical examination was entirely normal, except that the tip of the spleen was just palpable. Two days before admission his blood count showed: Hb 6.9 g./100 ml., total white count $3,200 /$ cu.mm. (polymorphs $56 \%$, eosinophils $6 \%$, basophils $2 \%$, lymphocytes $33 \%$, monocytes $3 \%$ ). There were 12 megaloblasts per 100 white cells, anisocytosis and poikilocytosis were fairly marked, and there was moderate polychromasia with some macrocytes. The changes suggested a haemolytic anaemia and/or haemopoietic factor deficiency. The day after admission the $\mathrm{Hb}$ had risen to $9.0 \mathrm{~g} . / 100 \mathrm{ml}$. and W.B.C. to $9,500 /$ cu.mm. (normal differential) with reticulocytes $6 \%$ and M.C.D. $7 \cdot 7 \mu$. Spherocytes 